\title{
Assessment of the Level of Soluble CD25 as a Marker for the Detection of Hepatocellular Carcinoma in Chronic Hepatitis C virus (HCV) Infected Patients
}

\author{
Shereen Z. Wagrees ${ }^{1}$, Hanaa F. Abdelaziz ${ }^{1}$, Basma Badr EL-Dein ${ }^{2^{*}}$ and \\ Seham A. Omar ${ }^{3}$
}

Departments of ${ }^{1}$ Clinical Pathology, Suez Canal University, ${ }^{2}$ Clinical Pathology, Port Said University, and IInternal Medicine, Suez Canal University, Egypt

\begin{abstract}
Background: Hepatitis C virus (HCV) is one of the most potential pathogens all over the world. Egypt has the highest HCV prevalence in the world. The hepatocellular carcinoma (HCC) is among cancers with the poorest outlook. The detection of HCC improves the outcome. The poor sensitivity of AFP underlines the need for a biomarker that can detect HCC. It was found that the CD25 is increased in patients with HCC. Aim: To assess the performance of serum soluble CD25 (SCD25) in the prediction of early HCC and compare it to a-fetoprotein (AFP); the classical biomarker of HCC. Patients and Methods: This study was a descriptive study. Patients were recruited from the Hepatology and Gastro-enterology department at Suez Canal University hospital. The study included 60 subjects, normal healthy individuals $(n=20)$, cirrhotic patients $(n=20)$ and HCC patients $(n=20) .2$ blood samples were collected from each patient one for liver profile and second stored for SCD25. Liver function tests, AFP and SCD25 were done to all the participants. Results: Our results show a highly significant increased levels of SCD25 in patients with cirrhotic liver and HCC compared to normal controls, $(p=0.001)$. No difference was found in $\mathrm{SCD} 25$ levels in HCC patients compared to liver cirrhosis patients $(p=0.862)$. Conclusion: SCD25 can differentiate HCC patients from normal healthy persons but not from cirrhotic patients. Thus, SCD25 cannot be used as an accurate diagnostic marker for HCC.
\end{abstract}

Key words: $\mathrm{SCD} 25$, HCC, Liver cirrhosis, Hepatitis C

\section{Introduction}

Hepatitis $C$ virus has been considered one of the most potential pathogens that have hindered the medical community all over the world. Indeed, since its discovery in 1989, hepatitis C virus (HCV) has been recognized as a major cause of chronic liver disease worldwide ${ }^{(1)}$. The data reported by WHO estimated that the prevalence of $\mathrm{HCV}$ infection is $2.2 \%$, and more than one million new cases were reported annually. Furthermore, an estimated $27 \%$ of cirrhosis and $25 \%$ of hepato-cellular carcinomas (HCC) 
worldwide occur in HCV-infected people ${ }^{(1,2)}$. Egypt has by far the highest $\mathrm{HCV}$ prevalence in the world(3). The estimated percentage of the Egyptian population in the 15-59 years age group who are positive for HCV antibody is 14.7 $\%$ (4). Over $80 \%$ of $\mathrm{HCV}$ infections in the Egyptian population are among individuals aged 30 years and above ${ }^{(4)}$. The HCV incidence appears to be driven by exposures within the health-care system ${ }^{(4-}$ 8). Chronic HCV has many harmful sequels. One of these sequels is the hepatocellular carcinoma that is among cancers with the poorest outlook, with fewer than $12 \%$ of all patients surviving at five years(9). The detection of hepatocellular carcinoma improves the outcome ${ }^{(10)}$. The poor sensitivity of AFP explains its absence from the American Association for the Study of Liver Disease (AASLD) practice Guidelines as a test recommended for screening of HCC. This substandard sensitivity underlines the need for a biomarker that is able to detect $\mathrm{HCC}^{(3,11)}$. The need for new marker for early detection of hepatocellular carcinoma was mandatory. Some studies found that soluble CD25 is increased in patients with hepatocellular carcinoma ${ }^{(12-17)}$. So, our study was aiming to measure serum level of $\mathrm{SCD} 25$ to provide a clue for early diagnosis of HCC.

\section{Subjects and Methods}

The study was conducted in Suez Canal university hospitals (gastroenterology and Hepatology unit) after obtaining an informed consent and the protocol was approved by faculty of medicine review board and ethical committee. Sixty patients in 3 groups, 20 of them were normal control; the second 20 were patients with liver cirrhosis due to hepatitis C viral infection and the last 20 were patients with hepatocellular carcinoma complicating hepatitis C viral infection. Healthy controls had matched age and sex with HCC patients. All included cases of HCC were diagnosed based on the presence of typical vascular enhancement pattern of liver lesion (s) in contrast enhanced dynamic CT scan or $M R{ }^{(18)}$. Diagnosis of cirrhosis was based on combined historical, clinical, laboratory and radiological findings. The staging of $\mathrm{HCC}$ was performed using the Barcelona Clinic Liver Cancer (BCLC) staging system. The following data were obtained for all patients: age, gender, ethnicity, etiology of HCC, BCLC stage. For the cirrhotic patients the following clinical data are obtained: age, gender, and ethnicity. All patients had complete laboratory profile including $C B C$, liver panel, creatinine as well as serum level of $\mathrm{SCD} 25$ and AFP. ELISA kit (R\&D systems Inc., USA) was used to quantify blood level of AFP while ELISA kit (Cell Science, Inc, Bldg Canton, MA) was used to measure serum level of sCD25. Whole blood samples were collected in the clinic from the three groups. About $10 \mathrm{~cm}$ were collected from each patient; $1.8 \mathrm{~mL}$ for the citrated tube for prothrombin time, the rest is for serum sample. Samples are processed for serum isolation. This was done immediately after clotting by centrifugation at approximately $1000 \mathrm{x} g$ for 10 minutes. Then the serum was removed and separated in Eppendroff tubes for chemistry and SCD25 assay.

\section{Statistical Analysis}

SPSS, version 21 for windows (Inc, Chicago, IL, USA) was used for all statistical analyses. Qualitative data were presented as frequency and percentage. Chi square and Fisher's exact tests were used to compare groups. Quantitative data were presented as mean and standard deviation. For nonparametric data, student test and MannWhitney $U$ test were used to compare 
level difference of $\mathrm{sCD} 25$ between two groups while ANOVA and Kruskal Wallis were used to compare level difference of sCD25. Between more than two groups. Receiver operator characteristic (ROC) curve analysis was used to generate sensitivity and specificity at different cutoffs. The best cutoff was set at the value where sensitivity and specificity were maximal. Correlation between serum level of SCD25 and laboratory parameters was assessed by Spearman's correlation coefficient. The statistical significance was set at P-value of less than 0.05 for all tests.

Table 1. Distribution of participants according to their sex \& age in different study groups

\begin{tabular}{|c|c|c|c|c|c|c|c|c|c|}
\hline & \multicolumn{2}{|c|}{ Control $(n=20)$} & \multicolumn{2}{|c|}{ Cirrhosis $(n=20)$} & \multicolumn{2}{|c|}{$\operatorname{HCC}(n=20)$} & \multirow{2}{*}{ Total } & \multirow{2}{*}{$\begin{array}{c}p^{-} \\
\text {value }\end{array}$} \\
\hline & & No. & $\%$ & No. & $\%$ & No. & $\%$ & & \\
\hline \multirow[t]{2}{*}{ Sex } & Male & 14 & $70 . \%$ & 14 & $70 \%$ & 14 & $70 \%$ & 42 & \multirow{2}{*}{0.517} \\
\hline & Female & 6 & $30 . \%$ & 6 & $30 \%$ & 6 & $30 \%$ & 18 & \\
\hline Age (yrs) & Mean \pm SD & \multicolumn{2}{|c|}{$57.1 \pm 12.3$} & \multicolumn{2}{|c|}{$50.4 \pm 9.7$} & \multicolumn{2}{|c|}{$58.4 \pm 5.6$} & 60 & 0.51 \\
\hline
\end{tabular}

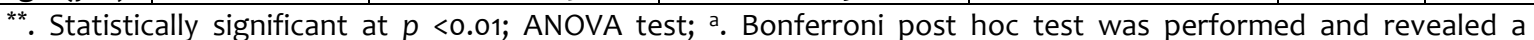
statistically significant difference between every pair of the groups

\section{Results}

The studied populations were mostly males representing $70 \%$ in all studied groups. The mean age was $58.4 \pm 5.6$ years in HCC group while was $50.4 \pm 9.7$ and $57.1 \pm 12.3$ years in cirrhotic and healthy controls respectively. Hepatitis C virus (HCV) represented the underlying etiology of cirrhosis HCC group and cirrhotic group as shown in table 1 . The mean SCD25 level was 11.1 $\pm 3.9,10.8 \pm 3.8$ and $5.0 \pm 2.0$ and $4.97 \pm 3.031 \mathrm{ng} / \mathrm{ml}$ in HCC, cirrhotic and healthy control groups respectively. There were statistically significant higher mean values of s CD25 in both HCC group and cirrhotic group than in control group $(p<0.001)$. Difference between Cirrhotic group and HCC group was not significant $(p=0.862)$ showed in table 3. The mean AFP level was $880.7 \pm 1557,42.6 \pm 169.6$ and $3.1 \pm 1.7 \mathrm{ng} / \mathrm{ml}$ in HCC, cirrhotic and healthy control groups respectively with significant statistical difference between HCC versus cirrhotic $(P=0.001)$. The rest of the laboratory data as well as their statistical differences between the studied groups are shown in Table 2. There were statistically significant higher mean values of ALT, AST, total bilirubin and direct bilirubin in HCC group than in cirrhotic group $(p<0.001)$, and significant higher mean values of ALT, AST, total bilirubin and direct bilirubin in cirrhotic group than in control healthy group $(p<0.001)$.

Table 2. Distribution of lab. Findings according to study groups

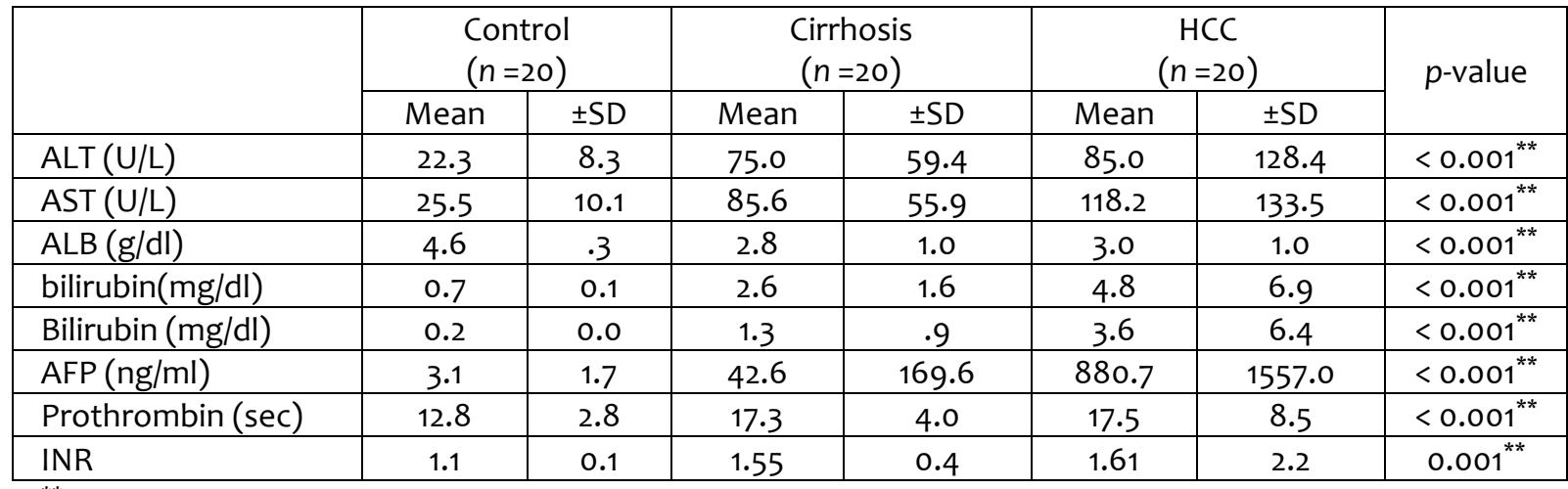

${ }^{* *}$. Statistically significant at $p<0.01 ;$ Kruskal Wallis test 
Table 3: Distribution of Soluble CD25 according to study groups

\begin{tabular}{|c|c|c|c|c|c|}
\hline \multicolumn{2}{|c|}{} & $\begin{array}{c}\text { Control } \\
(n=20)\end{array}$ & $\begin{array}{c}\text { Cirrhosis } \\
(n=20)\end{array}$ & $\begin{array}{c}\text { HCC } \\
(n=20)\end{array}$ & $p$-value \\
\hline $\begin{array}{l}\text { Soluble CD25 } \\
(\mathrm{pg} / \mathrm{ml})\left(\times 10^{3}\right)\end{array}$ & Mean \pm SD & $5.0 \pm 2.0$ & $10.8 \pm 3.8$ & $11.1 \pm 3.9$ & $\begin{array}{c}<0.001^{* * a} \\
0.862^{\mathrm{b}}\end{array}$ \\
\cline { 2 - 6 } & Minimum & 2.47 & 4.03 & 7.01 & \\
\cline { 2 - 6 } & Maximum & 11.08 & 16.72 & 21.79 & \\
\hline
\end{tabular}

${ }^{* *}$ Statistically significant difference at $p<0.01$; Mann-Whitney test; ${ }^{a}$. Difference was significant between control

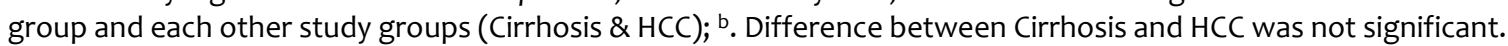

As regards prothrombin time there were significantly higher mean values of prothrombin time in HCC and cirrhotic groups than in control group $(\mathrm{p}<0.001)$. On the other hand, there were statistically significant lower mean values of albumin levels in HCC and in cirrhotic groups than in control group $(\mathrm{P}<0.001)$. Correlation analyses between $\mathrm{SCD} 25$ and laboratory parameters among the studied groups are shown in Table 4. There was statistically significant direct correlation between the levels of s CD25 and levels of ALT, AST, total bilirubin, direct bilirubin, prothrombin time $(p<0.001)$ and there is statistically significant inverse correlation between the levels of s CD25 and albumin levels $(p<0.001)$. $s C D 25$ performed well in predicting HCC presence among patients with cirrhosis; sensitivity and specificity were $65 \%$ and $65 \%$ respectively at a cut-off value of $10.22 \mathrm{ng} / \mathrm{ml}$ For prediction of HCC in patients with cirrhosis, while, sensitivity and specificity of AFP were $80 \%$ and $65 \%$ respectively at a cut-off value of $12.4 \mathrm{ng} / \mathrm{ml}$ in the same settings (Fig. 2, 3).

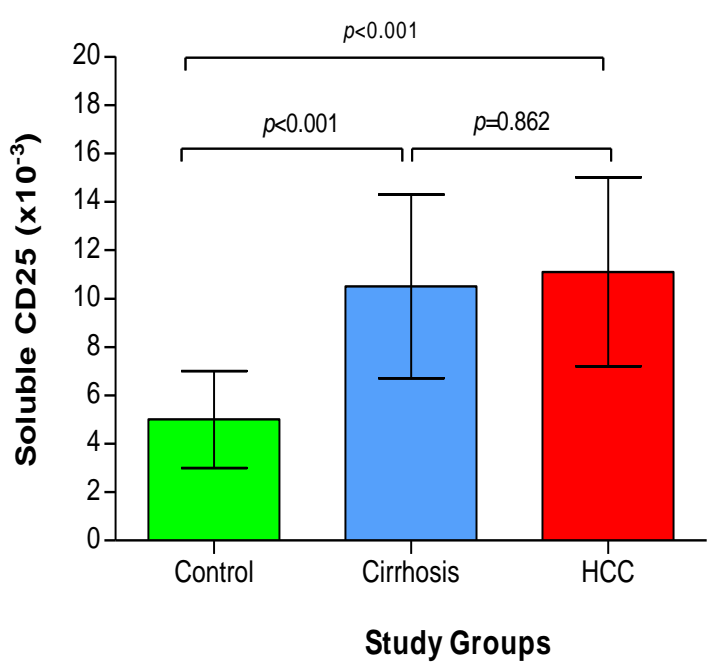

Figure 1: the relation between values of sCD25 and study groups

\section{Discussion}

Primary liver cancer often emerges as a complication of chronic liver disease, specifically cirrhosis. The most common cause of cirrhosis is chronic HCV infection $^{(14)}$. Aproximately $75 \%$ of patients with HCC present with advanced unresectable disease with some element of hepatic dysfunction ${ }^{(16)}$. There is a pressing need for a biomarker that detects the presence of HCC at a better capacity than AFP. 
Table 4. Correlation between Soluble $\mathrm{CD}_{2} 5$ and lab. findings

\begin{tabular}{|l|c|c|}
\hline \multirow{2}{*}{} & \multicolumn{2}{|c|}{ Soluble CD25 $\left(\times 10^{3}\right)$} \\
\cline { 2 - 3 } & $\begin{array}{c}\text { Spearman's Rank } \\
\text { Correlation }\end{array}$ & $p$-value \\
\hline ALT $(\mathrm{U} / \mathrm{L})$ & $0.423^{* *}$ & $0.001^{* *}$ \\
\hline AST $(\mathrm{U} / \mathrm{L})$ & $0.447^{* *}$ & $<0.001^{* *}$ \\
\hline ALB $(\mathrm{g} / \mathrm{dl})$ & $-0.577^{* *}$ & $<0.001^{* *}$ \\
\hline T.bili $(\mathrm{mg} / \mathrm{dl})$ & $0.441^{* *}$ & $<0.001^{* *}$ \\
\hline D.bili $(\mathrm{mg} / \mathrm{dl})$ & $0.524^{* *}$ & $0.020^{*}$ \\
\hline AFP $(\mathrm{ng} / \mathrm{ml})$ & $0.300^{*}$ & $<0.001^{* *}$ \\
\hline PT $(\mathrm{sec})$ & $0.496^{* *}$ & $0.001^{* *}$ \\
\hline INR & $0.422^{* *}$ & \\
\hline$* *$ & Correlation is statistically significant at $\mathrm{p}<0.01$ (two-tailed). \\
${ }^{*}$. Correlation is statistically significant at $\mathrm{p}<0.05$ (two-tailed).
\end{tabular}

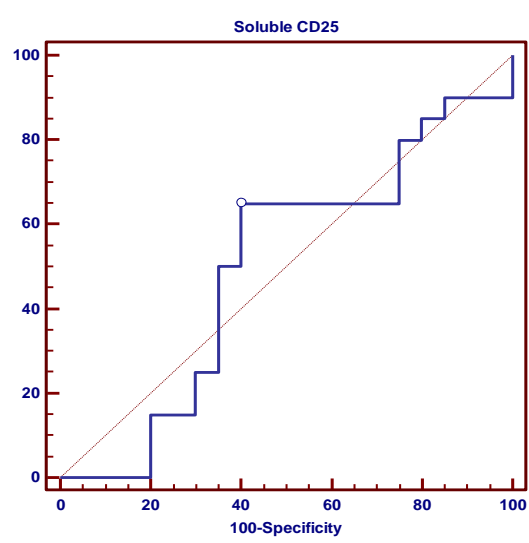

Figure 2: $\mathrm{ROC}$ curve for $\mathrm{SCD} 25$ in diagnosis of $\mathrm{HCC}$ among HCV-patients $(\mathrm{n}=20)$

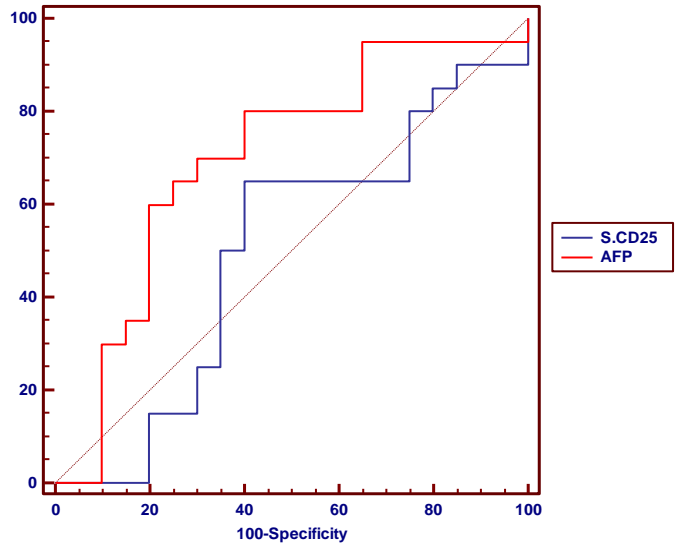

Figure 3: ROC curves of SCD25 and AFP in the diagnosis of HCC among HCV-patients $(n=20)$
In our study, we examined the relation between S CD25 and the presence of HCC in an attempt to find a reliable measurable predictor biomarker to detect the presence of HCC, we found that the mean age of the control group was 57.1 \pm 12.3 years, the mean age of the cirrhotic group is $50.4 \pm 9.7$ years and the mean age of the HCC group is $58.4 \pm 5.6$ years. This is in agreement with the study of Mohamed et al. $(2013)^{(10)}$ who reported that the frequent age category affected by HCC was between 51 and 60 years as the progress of the disease takes time from hepatitis to cirrhosis to HCC. In this study, $\mathrm{HCC}$ is more presented in males than in females this is in agreement with AbdelSamee et al $2017(2017)^{(16)}$ who presented that men are two to three times higher than women, this is due to high prevalence of $\mathrm{HCV}$ in males than in females. The same results were reported in Egyptians series by El-zayadi et al. (2009)(3). Similar results about higher prevalence in males than in females were found in a recent African study performed by Ayele and Gebre-Selassie. (2013) ${ }^{(11)}$. from a total of 12opatients with chronic hepatitis C, 76 (63.3\%) were males and 44 (36.7\%) females (male to female ratio of 1.7: 1). In this study, there were statistically significant higher mean values of ALT and AST in patients with liver cirrhosis with the mean level was $75 \pm 59.4(\mathrm{U} / \mathrm{L})$ and $85.6 \pm 55.9(\mathrm{U} / \mathrm{L})$ respectively, And more higher levels of ALT and AST in patients with HCC with the mean level $85 \pm 128.4$ $(\mathrm{U} / \mathrm{L})$ and $118.2 \pm 133.5(\mathrm{U} / \mathrm{L})$ respectively $(p<0.001)$. This do not come in agreement with Lee et al. (2010) and Park et al. 
$(2012)^{(13,14)}$, who reported that serum ALT can be elevated in persons with normal liver histology and can be normal in patients with advanced liver fibrosis. There were statistically significant low mean values of serum albumin in both liver cirrhosis and HCC groups being $2.8 \pm 1$ $(\mathrm{g} / \mathrm{dl})$ and $3.0 \pm 1 \quad(\mathrm{~g} / \mathrm{dl})$ respectively $(p<0.001)$. This comes in agreement with Brian et al. $(2014)^{(15)}$, who reported that the incidence of hepatocellular carcinoma is high in patients with advanced cirrhosis consequently these HCC patients have marked hypoalbuminemia. There were also high levels of serum total bilirubin, direct bilirubin and prothrombin time. This comes in agreement with Brian et al. $(2014)^{(15)}$, who reported that HCC patients with elevated serum bilirubin have worse prognosis. There were statistically significant higher mean values of AFP in HCC group being 880.7 $\pm 1557.0(\mathrm{ng} / \mathrm{ml})$ than in cirrhotic group with the mean being $42.6 \pm 169.6(\mathrm{ng} / \mathrm{ml})$ and in both groups (cirrhotic and HCC) than the

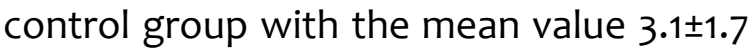
$(\mathrm{ng} / \mathrm{ml})(p<0.001)$. Similarly Grizzi et al. $(2007)^{(16)}$ On the other hand, Cabrera et al. $(2012)^{(17)}$, reported that normal AFP levels are present in as many as 30\% of patients with HCC at the time of diagnosis and usually remain low even with advanced HCC. In this study the sensitivity of AFP was $65.0 \%$ and the specificity was $80.0 \%$ at a cutoff value of $>12.4$ ( $\mathrm{ng} / \mathrm{ml})$. In a previous study by Cabrera et al. (2012)(17), the sensitivity was $53.8 \%$ and the specificity was $86.8 \%$ at a cutoff value of $32.8(\mathrm{ng} / \mathrm{ml})$ and in a study by Rizk et al. $(2015)^{(19)}$, the sensitivity of AFP was $73.3 \%$ and the specificity was $86.6 \%$ at a cutoff value of $21.45(\mathrm{ng} / \mathrm{ml})$. These finding may indicate difference in analytical methods and statistical cutoff points. Our results show highly significant increased levels of sCD25 in patients with cirrhotic liver and $\mathrm{HCC}$ as compared to normal controls, the mean value of the control group is $5 \pm 2$ $(\mathrm{pg} / \mathrm{ml})$, the mean value of the cirrhotic group is $10.8 \pm 3.8(\mathrm{pg} / \mathrm{ml})$ and the mean value of the HCC group is 11.1 \pm 3.9 $(\mathrm{pg} / \mathrm{ml})(p<0.001)$. This comes in agreement with cabrera et al. (2012)(17), who reported that SCD 25 was significantly increased in patients with cirrhosis than in healthy group. Also, our results show significant increased levels of s CD25 in patients with HCC as compared to healthy group. This also comes in agreement with Caberera et al (2012)(17) and Abdel-Samee et al $2017(2017)^{(16)}$. In this present study, there was no significant increase in the level of S CD25 in patients with $\mathrm{HCC}$ than in pateints with liver cirrhosis $(p=0.862)$. This was not in agreement with Caberera et al (2012)(17), who reported that the levels of S CD25 were significantly higher in patients with HCC than in normal group and than in patients with liver cirrhosis. A study done by Ararat et al. (2011) (20), Showed that the level of S CD25 in the serum of HCC patients was significantly higher (mean $12799 \mathrm{pg} / \mathrm{ml}$ ) than that in the patients with cirrhosis (mean $3585 \mathrm{pg} / \mathrm{ml}$ ). This analysis found that $S C D 25$ possess a sensitivity of $65 \%$ at a cutoff value of $>10.22 \times 10^{3}$ $(\mathrm{pg} / \mathrm{ml})$ for the presence of $\mathrm{HCC}$ and $\mathrm{a}$ specificity of $65.0 \%$ at the same cutoff value and warrants an additional investigation as a potential screening test. This do not come in agreement with Ararat et al (2011)(20) who reported that at a cutoff value of $>5.15 \times 10^{3}(\mathrm{pg} / \mathrm{ml}), \mathrm{sCD} 25$ has a sensitivity of $62.1 \%$ and a specificity of $83.3 \%$, our results are lower this may be due to genetic difference, environmental factors and duration of HCC. When comparing S CD25 with AFP we found that the specificity of AFP (80.0\%) was higher than that of S CD25 (65.0\%). The positive predictive value of $S \mathrm{CD}_{2} 5$ in the present study was 65.0 at a cutoff value of $>10.22$ $x 10^{3}(\mathrm{pg} / \mathrm{ml})$ compared to AFP, which has 
a positive predictive value of $69.6 \%$ at a cutoff value of $>12.4 \mathrm{ng} / \mathrm{ml}$ ). The negative predictive value of $s C_{2} 5$ in the present study is $65.0 \%$ at a cutoff value of $>10.22 \mathrm{x}$ $10^{3}(\mathrm{pg} / \mathrm{ml})$ as compared to the negative predictive value of AFP, which has a negative predictive value of $69.6 \%$ at a cutoff value of $>12.4(\mathrm{ng} / \mathrm{ml})$. Soluble CD25 is correlated to the severity of liver disease in the form of negative correlation between s CD25 and albumin $(p<0.001)$ and significant positive correlation between S CD25 and INR $(p<0.001)$. This comes in agreement with Rizk et al $(2015)^{(19)}$ who reported the same results.

\section{Conclusions}

SCD25 sounds not to be a good marker for predicting early HCC. CD25 can differentiate HCC patients from normal healthy persons but not from cirrhotic patients.

\section{References}

1- Abbassy HA and Elbanna AA 2016. Noninvasive Markers for the Assessment of Liver Fibrosis and Cirrhosis in Egyptian Patients with Chronic Hepatitis C and Schistosomiasis Coinfection. J Medical science and clinical research 2016 vol.4(12);14773-14780.

2- Miller FD and Abu-Raddad LJ (2010) Evidence of intense ongoing endemic transmission of hepatitis $C$ virus in Egypt. Proc Nat Acad Sci USA 107: 14757-14762.

3- El-Zanaty F and WayA (2009): Egypt Demographic and Health Survey (2008). Cairo: National Population Council, El-Zanaty and Associates, and ORC Macro.p 431

4- Saleh DA, Shebl FM, El-Kamary SS, et al (2010): Incidence and risk factors for community-acquired hepatitis $\mathrm{C}$ infection from birth to 5 years of age in rural Egyptian children. Trans $\mathrm{R}$ Soc Trop Med Hyg 104: 357-363.
5- Esmat G, Hashem M, El-Raziky M, et al (2011): Hepatocellular carcinoma. N Engl J Med. 365:1118-1127.

6- El-Serag HB (2011): Hepato-cellular carcinoma. N Engl J Med; 365: 11181127.

7- Cabrera R, Ararat M and Cao M (2010): Hepatocellular carcinoma: immunopathogenesis: clinical evidence for global $\mathrm{T}$ cell defects and an immunomodulatory role for soluble CD25 (sCD25). Dig Dis Sci 55: 484-495.

8- Mühlberger N, Schwarzer R, Lettmeier $B$, et al (2009): HCV-related burden of disease in Europe: a systematic assessment of incidence, prevalence, morbidity, and mortality. BMC Public Health.2009; 9: 34.

9- Sherman M (2011): current status of AFP testing. Gastroenterol Hepatol (NY) 7: 113-114.

10- Mohamed YA, Mumtaz RG, Riome S, Miller D and Abd-Raddad LJ (2013): the epidemiology of hepatitis $C$ virus in Egypt;1471-2334.

11- Ayele AG and Gebre-Selassie S (2013): Prevalence and Risk Factors of Hepatitis B and Hepatitis C Virus Infections among Patients with Chronic Liver Diseases in Public Hospitals; org/10.1155/2013/56382.

12- Tatsuo S, Masahiko S, Kenji G, et al (2018). Prognostic impact of soluble intercellular adhesion molecule-1 in hepatocellular carcinoma: Oncology Letters 16: 6013-6018, 2018

13- Lee JK, Shim JH, Lee HC, et al (2010): Estimation of the healthy upper limits for serum alanine aminotransferase in Asian populations with normal liver histology. Hepatology; 51:1577-1583.

14- Park HN, Sinn DH, Gwak GY, et al (2012): Upper normal threshold of serum alanine aminotransferase in identifying individuals at risk for chronic liver disease. Liver Int; 32:937944.

15- Brian I. C, Vito G, Giannini, et al (2014): association of abnormal plasma bilirubin with aggressive $\mathrm{HCC}$ phenotype; PLOS MED 41(2): 252-258. 
16- Grizzi F, Franceschini B, Hamrick C, et al (2007): Usefulness of cancer-testis antigens as biomarkers for the diagnosis and treatment of hepatocellular carcinoma. J Transl Med; 5:3.

17- Cabrera R, Fitian Al, Ararat M. et al (2012): serum level of $S$ CD25 as a marker for HCC; Oncol Lett. 4(4): 840846.

18- Abdel-Sameea E, Zakareya T, Metwaly $\mathrm{KH}$, et al 2017. Serum soluble CD25 in hepatocellular carcinoma, shall we be able to change the natural history? 2017. J Cancer and Tumor Int, 5: 4 2017

19- Rizk E, Zakaria S and Farouk N (2015): soluble CD25 and hepatocellular carcinoma. Int J advanced Res; 3(5); 658-664.

20- Ararat $M$, Fitian Al, Brusko $T$, et al (2011): the soluble form of IL-2 (s CD25) as a novel biomarker for HCC. J clin oncology 29. 